\title{
Microtubule Biomechanical Properties under Deformation and Vibration
}

\author{
Ramana Pidaparti ${ }^{1}{ }^{\circledR}$, Jongwon Kim² \\ ${ }^{1}$ College of Engineering, University of Georgia, Athens, USA; ${ }^{2}$ Department of Radiation Oncology, University of \\ Arizona, Tucson, USA
}

Correspondence to: Ramana Pidaparti,rmparti@uga.edu

Keywords: Microtubule, Vibration, Deformation, Finite Element Method, Biomechanical Properties

Received: October 22, $2021 \quad$ Accepted: January 23, $2022 \quad$ Published: January 26, 2022

Copyright $\odot 2022$ by author(s) and Scientific Research Publishing Inc.

This work is licensed under the Creative Commons Attribution International License (CC BY 4.0).

http://creativecommons.org/licenses/by/4.0/

\section{(c) (i) Open Access}

\section{ABSTRACT}

Microtubules (MT) are of great engineering importance due to their potential applications as sensors, actuators, drug delivery, and others. The MT properties/mechanics are greatly affected by their biomechanical environment and it is important to understand their biological function. Although microtubule mechanics has been extensively studied statically, very limited studies are devoted to the biomechanical properties of microtubule undergoing deformation and vibration. In this study, we investigate the biomechanical properties of the microtubule under bending deformation and free vibration using 3D finite element analysis. Results of force-deformation and vibration frequencies and mode shapes obtained from the finite element analysis are presented. The results indicate that the force-deformation characteristics vary with time/phases and become non-linear at higher time intervals. The modes of MT vibration and frequencies are in the $\mathrm{GHz}$ range and higher modes will involve combined bending, torsion and axial deformations. These higher modes and shapes change their deformation which might have implications for physiological and biological behavior, especially for sensing and actuation and communication to cells. The bending force-deformation characteristics and vibration modes and frequencies should help further understand the biomechanical properties of self-assembled microtubules.

\section{INTRODUCTION}

Microtubules (MTs) are long filamentous intracellular structures (25 $\mathrm{nm}$ in diameter and quite long) that are formed through a self-assembly process with tubulin dimers ( $\alpha$ and $\beta$ tubulins) as the basic building blocks. MTs are responsible for various biological functions such as cell division, organization of intracellular structure and transport, and flagellar motility [1-3]. Microtubules in living cells are frequently 
subjected to bending/tension/torsion as well as vibration, and these behaviors play an important role in their biomechanical behavior. Also, individual tubulins within microtubules may exist in different states, that can change on various time scales, thus exhibiting multifunctional properties of MTs.

Microtubules, either straight or curved, exhibit anisotropic properties [4] as well as length dependent mechanical properties [5]. Also, the binding of microtubule associate proteins (MAPs) greatly affects the mechanical characteristics of MTs [6]. Due to the above combination of properties, MTs can function in many activities including maintaining the cell shape, mitosis, flagella and cilia movements, and cargo transportation [7]. Several studies [8] were published to further explain these properties observed in experiments to better understand the mechanical properties of MTs.

The mechanics of individual MTs have been extensively studied, specifically the static and molecular mechanisms $[9,10]$. There has been extensive study on the vibration dynamics and fluctuations of microtubules in the quest for understanding the relation between microtubule material properties and their ability to carry out several functions in cells. Several studies related to MT vibrations have been conducted due to their importance and impact on the intra-cellular processes. Li et al. [11] investigated the beam-like bending vibration of microtubules using $3 \mathrm{D}$ models. They also investigated the electromechanical vibration of microtubules and its application to sensors [12]. The transverse vibration of MTs varies from 18.4 to $240.3 \mathrm{MHz}$ under an electric field and the vibrational property changes may be due to tubulin interactions that might serve as a sensor for monitoring physiological processes. Aria and Biglari [13] used a nonlocal strain gradient model to study buckling and vibration responses of microtubules in axons and found many interesting aspects of softening and hardening at higher modes of vibration. Kucera, Havelka and Cifra [14] conducted a mini-review to analyze models of microtubule vibration dynamics and pointed out the limitations of not accurately predicting the physiological or biological behavior. Havelka et al. [15] also investigated the deformation pattern of vibrating microtubules based on an atomistic approach and found that anisotropy determined by bonds between tubulins greatly affects the vibration frequencies. The mechanical properties (Young's modulus) of microtubules were estimated through dynamic simulation and finite element method [16] and compared to those with existing literature. Wang, Ru and Mioduchhowski [17] developed an orthotropic shell model to investigate microtubule properties under free vibration and showed the importance of vibrational models in both longitudinal and circumferential directions.

Kim et al. [18] developed a finite element model of straight protofilaments and investigated the effects on their mechanical behavior under different loadings. They found that the protofilament behaves non-linearly under tension and torsion but linearly under bending. Pidaparti and Jakkam [19] investigated the mechanical properties of curved protofilaments of microtubules and found that curvature greatly affects the mechanical behavior, especially the stress-strain relationships. It is evident that from Refs. $[18,19]$ that both deformation and stiffness of microtubule/protofilaments greatly affect their stiffness under multiple loadings. Also, the protofilament/MT curvature influences the mechanical behavior through maximum stresses and stiffness in the MTs [19]. Due to the important role played by the tubulins and their interactions in microtubule self-assembly, it is important to further investigate their vibrational behavior.

In this study, we investigated the vibrational frequencies and mode shapes of microtubules through 3D finite element analysis. After creating the MT geometry and assigning the properties, bending deformation and free vibrational analyses were carried out. The results of force-deformation and free vibration characteristics obtained from the finite element analysis are presented and discussed.

\section{COMPUTATIONAL APPROACH}

A microtubule configuration consisting of a cylindrical hollow tube made up of protofilaments fused together in parallel to each other along the circumferential direction was considered in the computations. Typically, a microtubule is composed of $8-13$ protofilaments, and it usually has an inner diameter of 15.4 $\mathrm{nm}$ and an outer diameter of $25 \mathrm{~nm}$ [20]. The length of MT can vary from tens of nanometers to hundreds of microns. We created 8 protofilaments along the circumferential direction, and each protofilament was composed of 10 spherical tubulins with $\alpha$-tubulin and $\beta$-tubulin forming a dimer as shown in Figure 1 . It 


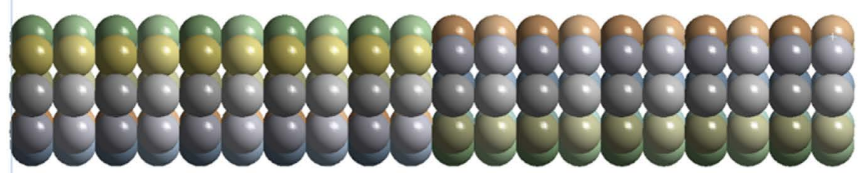

(a) Microtubule Geometry
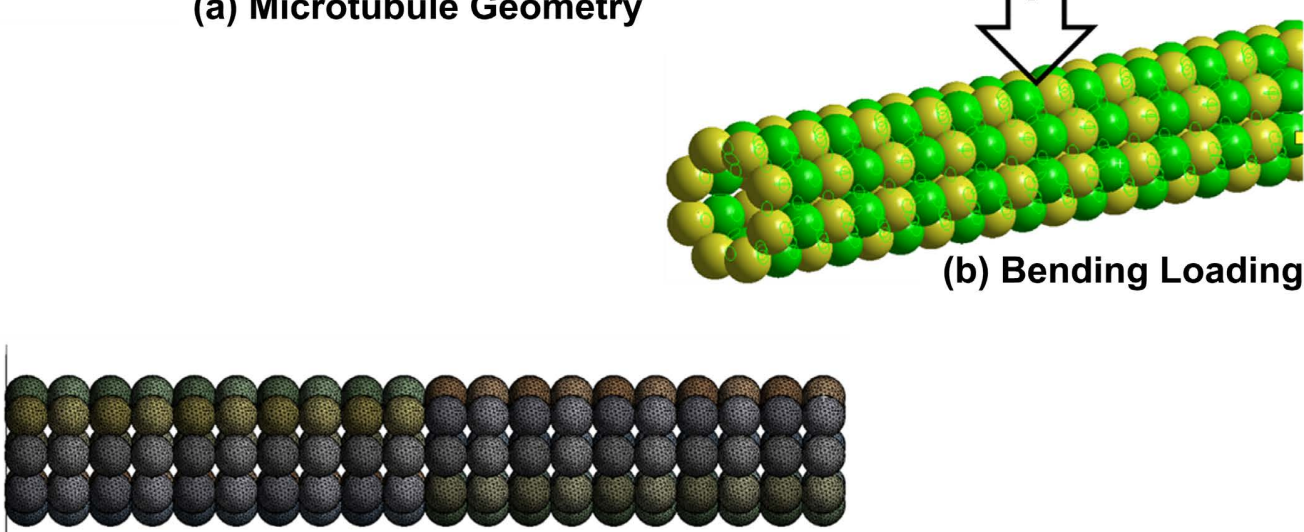

(c) Finite Element Mesh

Figure 1. Microtubule considered for analysis, (a) geometry; (b) bending loading; and (c) finite element mesh.

is assumed that each tubulin is of $6 \mathrm{~nm}$ diameter with inner and outer microtubule diameter of $12 \mathrm{~nm}$ and $24 \mathrm{~nm}$, respectively. The Microtubule was generated using ANSYS DesignModuler and each tubulin was connected with spring at the contact region which represents MT protein elasticity. The finite element model (FEM) of the microtubule is also shown in Figure 1.

The spring constants and material properties adopted in our study are obtained from the literature $[21,22]$. The stiffness of an individual $\alpha$ tubulin is around $11 \mathrm{~N} / \mathrm{m}$ while that of a $\beta$ tubulin is around 15.6 $\mathrm{N} / \mathrm{m}$ as per a molecular dynamics (MD) study [21]. The shear modulus of the spherical shell model is set to be $400 \mathrm{MPa}$ [23]. $\alpha$ tubulins are not differentiated from $\beta$ tubulins in our model due to their structural similarity and similar mechanical performance. These data are listed in Table 1.

All simulations were performed using the software ANSYS 16.0 Mechanical package. We used ANSYS workbench to develop our 3D finite element model and analyzed it under a nonlinear material condition. The computational model adopted here consists of 104,000 nodes and 103,350 shell elements. Experimental observations have shown that MTs frequently bend in living cells, with a mean curvature of about $0.4 \mathrm{rad} / \mathrm{nm}$ in fibroblast cells [24]. Hence, the bending of MT was investigated similar to the study using a nanoindentation approach [25] to estimate the bending deformations. The analysis results of force-deformation and free vibration modes are presented.

\section{RESULTS AND DISCUSSION}

\subsection{Force-Deformation Characteristics under Bending}

Finite element analysis was carried out to investigate the force-deformation characteristics and results were compared to those obtained from a nanoindentation and in-silico studies [25]. Figure 2 shows the bending deformation of the MT at four different phases (times) obtained from the finite element analysis. It can be seen that bending deformation increases with increasing time. The force-deformation characteristics at various times are shown in Figure 3. It can be seen that initially the MT is stiff and starts to become softer and non-linear with increasing deformation and time.

The results of maximum displacement and maximum strains at various times/phases are presented in Figure 4. It can be seen from Figure 4 that the maximum displacements and strains increase with increasing times during the bending loading on the MT. It is interesting to note that the MT bending deformation is 
Table 1. Parameters used to construct FE model for microtubules

\begin{tabular}{cc}
\hline Parameter [Ref] & Value \\
\hline Microtubulin radius [21, 22] & $12.5 \mathrm{~nm}$ \\
Microtubulin surface area & $157 \mathrm{~nm}^{2}$ \\
Microtubulin volume & $8.2 \mu \mathrm{m}^{3}$ \\
Each contract area & $3.6 \mathrm{~nm}^{2}$ \\
Initial shear modulus [23] & $400 \mathrm{MPa}$ \\
Microtubule spring constant [22] & $47.1 \mathrm{nN} / \mathrm{nm}$ \\
\hline
\end{tabular}

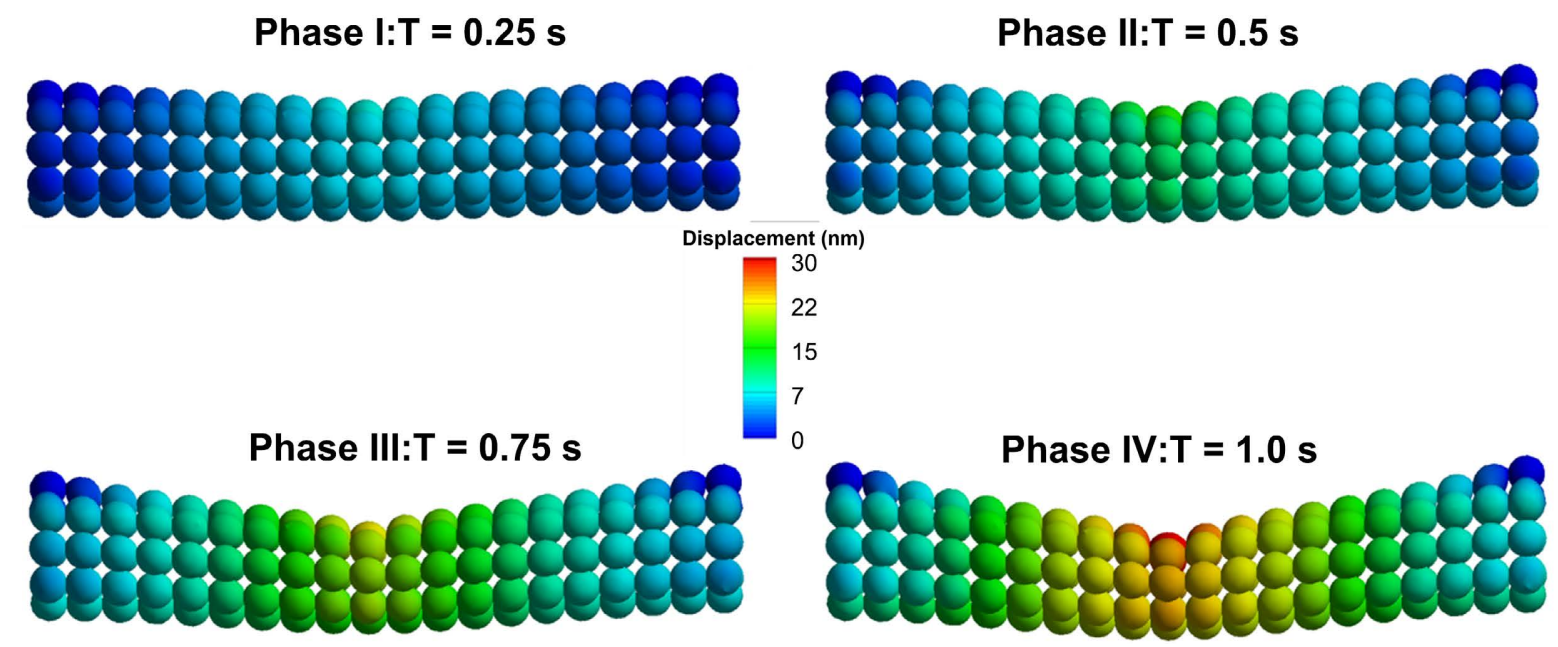

Figure 2. Microtubule bending deformation at four different times/phases.

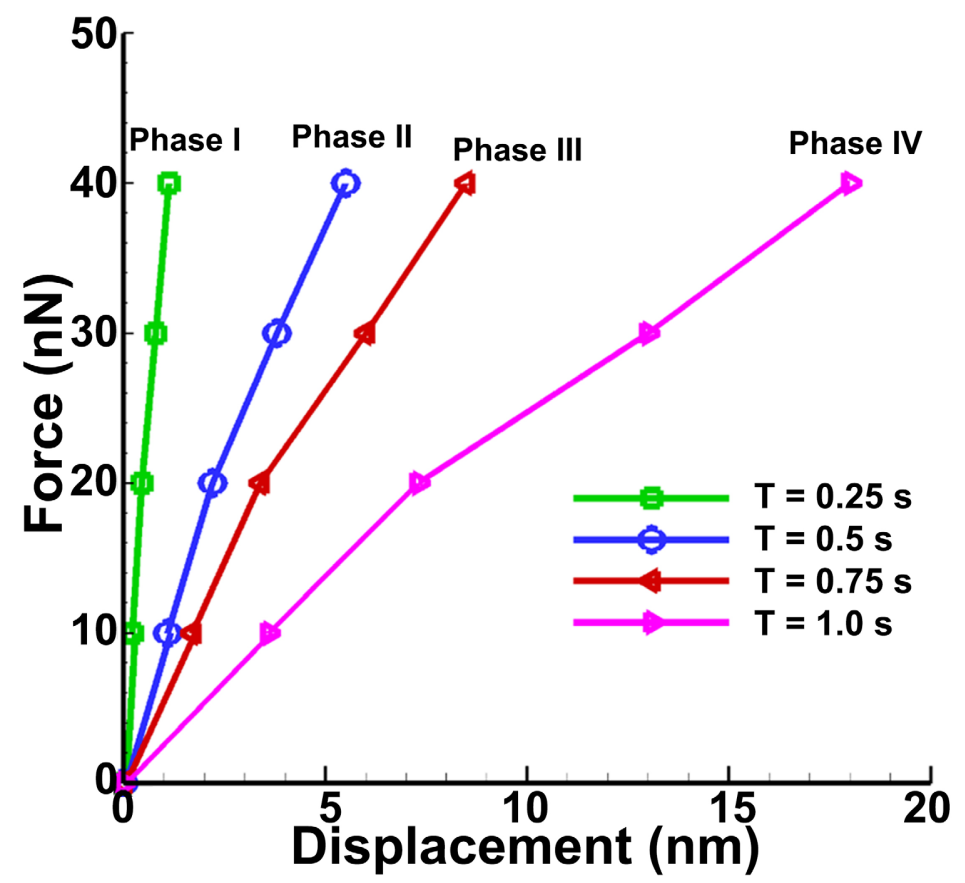

Figure 3. Force-deformation of microtubule under bending. 


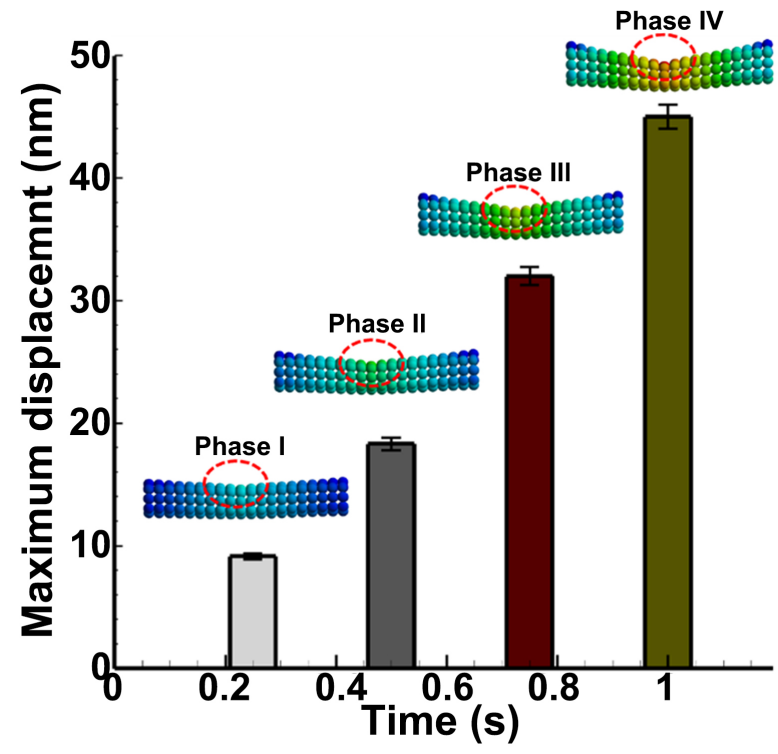

(a)

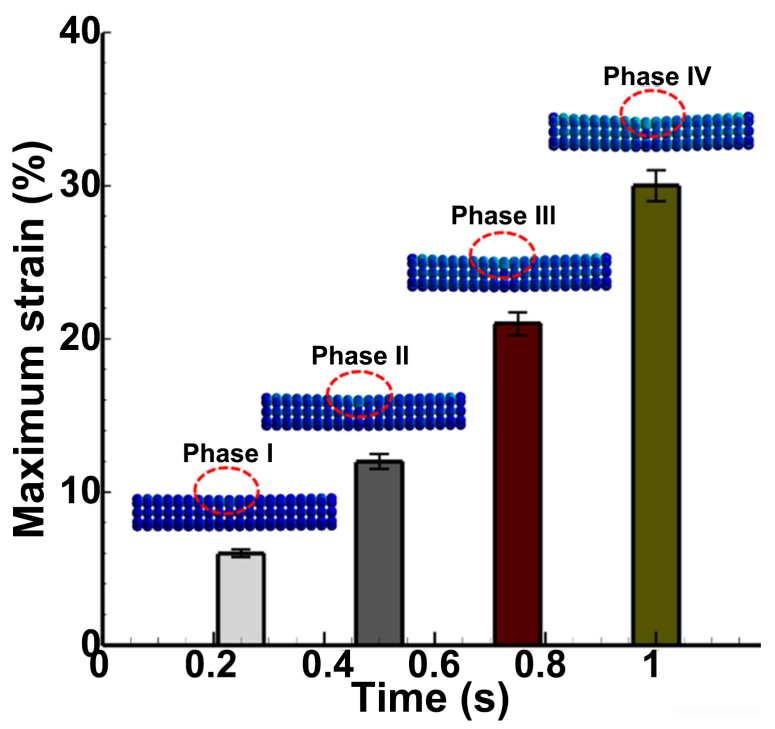

(b)

Figure 4. Maximum displacement (a) and maximum strains (b) of microtubule under bending at four different times.

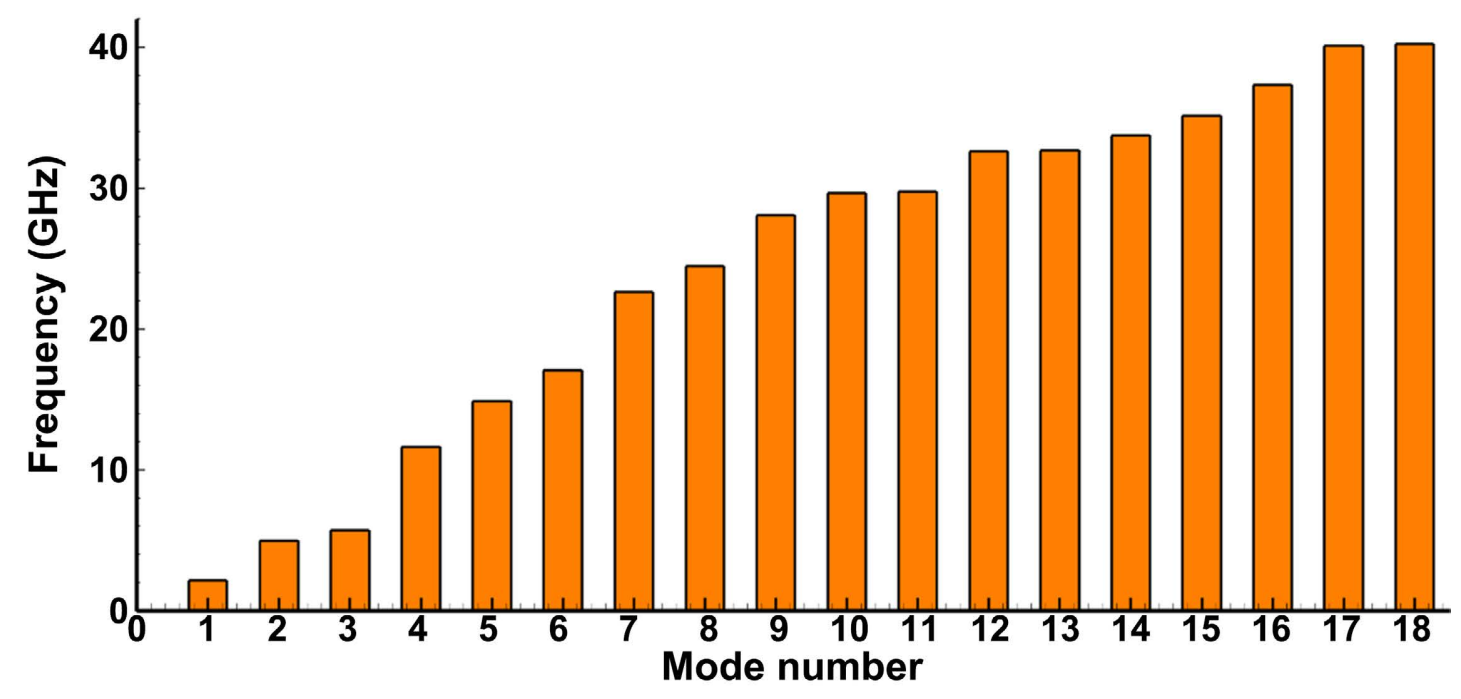

Figure 5. First 18 vibration frequencies of the microtubule obtained from the analysis.

within the range (5 - $25 \mathrm{~nm}$ ) of those obtained from molecular dynamics simulations [25], thus validating the computational model. Also, the force-deformation characteristics vary from a linear to a non-linear fashion with different phases of bending deformation. This shows that the MT can adapt to various loading conditions through bending deformations.

\subsection{Free Vibration Characteristics}

The results of vibration frequencies obtained for the MT configuration from the finite element analysis are presented in Figure 5. The frequencies for the first 18 modes of vibration for the MT considered are in the $\mathrm{GHz}$ range. This finding is consistent with those obtained in previous studies [15]. The mode shapes for these 18 frequencies are presented in Figure 6. The primary modes include bending (mode 4), torsion 
(mode 7), coupled axial and bending (mode 8 ) and coupled bending and torsion (mode 11). Higher modes involve combinations of higher bending, twisting and axial (modes 14,16,17).

It is interesting to see how the MT can accommodate multiple vibration modes and their combination. This is very important for MT function as it can serve as a multifunctional unit with shape organization, nanomaterial, sensing and actuation capabilities [7, 12]. Also, the vibration modes are compared qualitatively with those obtained from molecular dynamics simulations in Figure 7. A very good agreement is

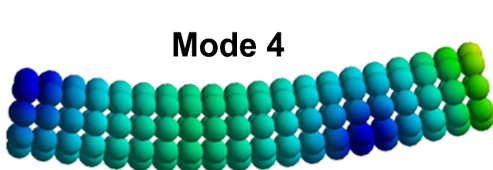

Mode 5

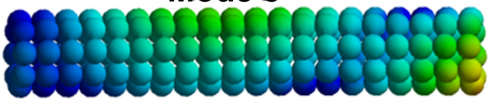

Mode 6

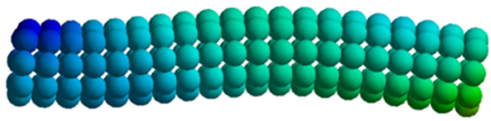

Mode 7

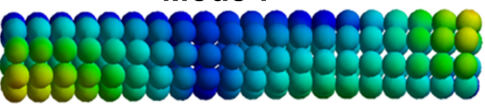

Mode 8

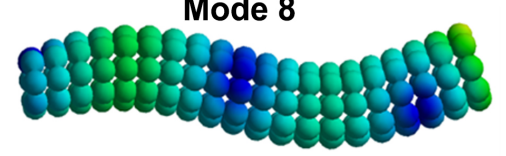

Mode 9

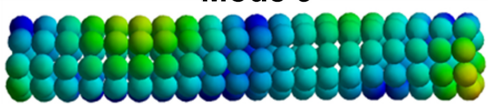

Mode 10

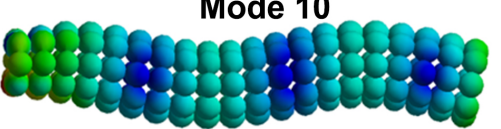

Mode 11

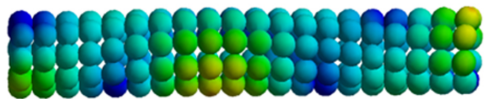

Mode 12

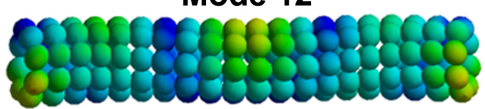

Mode 13

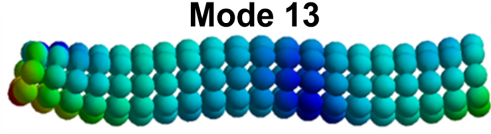

Mode 14

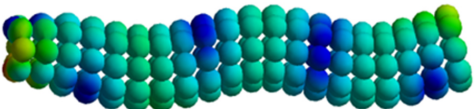

Mode 15

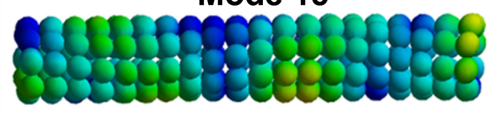

Mode 16

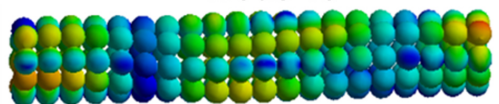

Mode 17

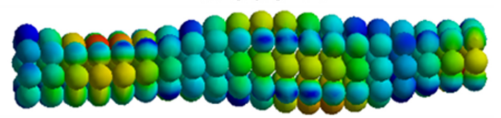

Mode 18

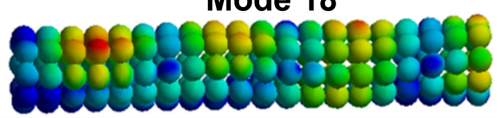

Figure 6. Mode shapes of the microtubule obtained from the analysis.

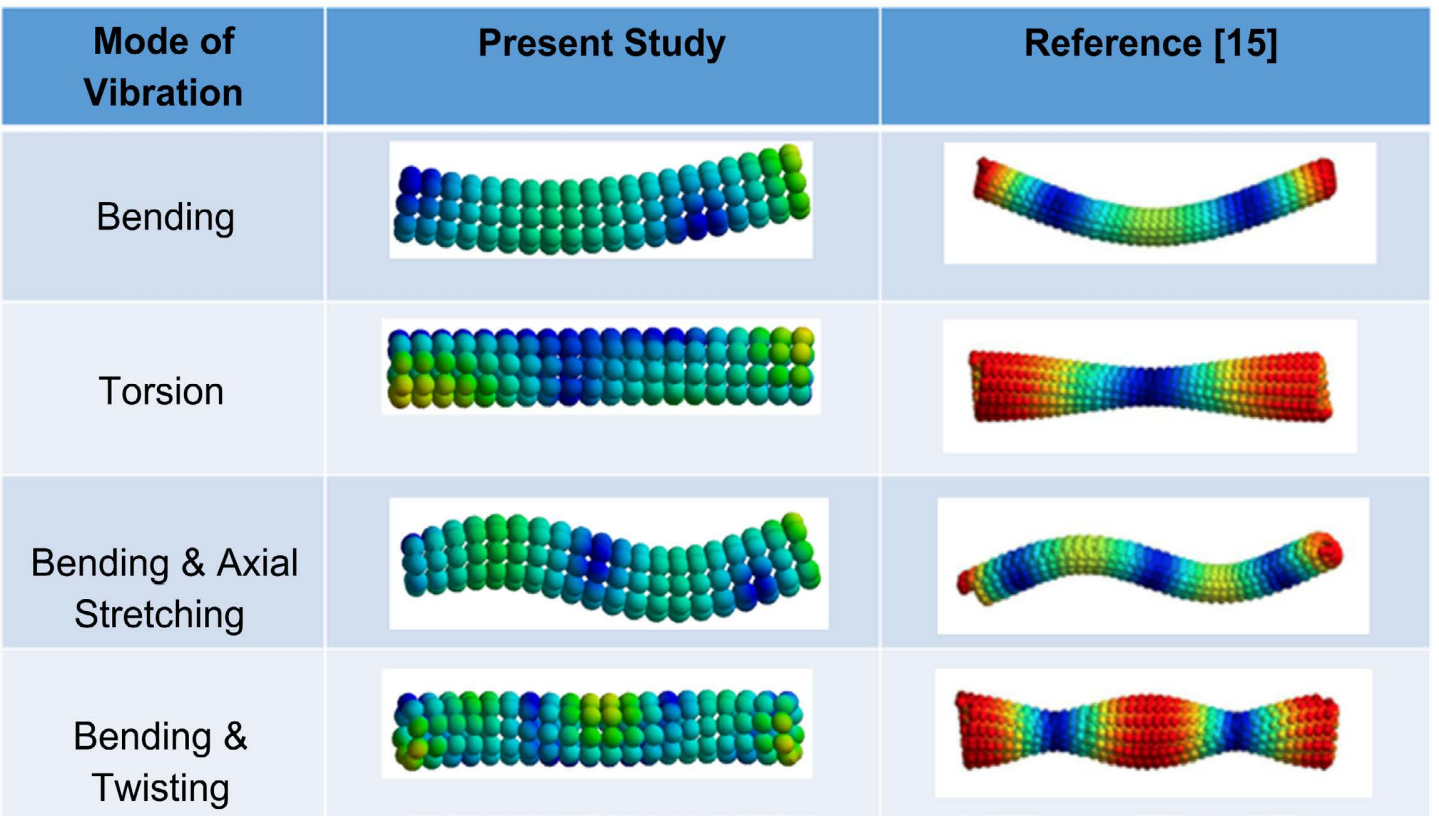

Figure 7. Comparison of first few primary mode shapes of the microtubule with those obtained from molecular dynamics [15]. 
seen. These vibration modes reflect the deformations resulting from tubulin and their binding sites in forming the MT self-assembly [25].

\section{CONCLUDING REMARKS}

In this study, a 3D finite element model for microtubules based on molecular level information was adopted to perform both bending deformation and free vibration analyses. The results of bending deformation characteristics with increasing time were compared with molecular dynamics analysis results and the deformations were found to be within the range of $5-30 \mathrm{~nm}$. The results of vibration modes and frequencies also compared well both in frequency ranges and modes of vibration. Additionally, the higher modes of vibration involved a combination of bending, axial, and torsion modes. These results further highlight the MT multifunctionality in accommodating coupled deformations, and suggest the potential for sensor and actuator applications of MT.

\section{ACKNOWLEDGEMENTS}

The authors thank NSF for supporting this work through a grant CDS\&E-1610812.

\section{CONFLICTS OF INTEREST}

The authors declare that no conflict of interest regarding the publication of this paper.

\section{REFERENCES}

1. Alberts, B. (2017) Molecular Biology of the Cell. Garland Science, New York. https://doi.org/10.1201/9781315735368

2. Valdman, D., Atzberger, P.J., Yu, D., Kuei, S. and Valentine, M.T. (2012) Spectral Analysis Methods for the Robust Measurement of the Flexural Rigidity of Biopolymers. Biophysical Journal, 102, 1144-1153. https://doi.org/10.1016/j.bpj.2012.01.045

3. Dogterom, M. and Surrey, T. (2013) Microtubule Organization in Vitro. Current Opinion in Cell Biology, 25, 23-29. https://doi.org/10.1016/j.ceb.2012.12.002

4. Hawkins, T., Mirigian, M., Yasar, M.S. and Ross, J.L. (2010) Mechanics of Microtubules. Journal of Biomechanics, 43, 23-30. https://doi.org/10.1016/j.jbiomech.2009.09.005

5. Pampaloni, F., et al. (2006) Thermal Fluctuations of Grafted Microtubules Provide Evidence of a Length-Dependent Persistence Length. Proceedings of the National Academy of Sciences of the United States of America, 103, 10248-10253. https://doi.org/10.1073/pnas.0603931103

6. Verhey, K.J. and Gaertig, J. (2007) The Tubulin Code. Cell Cycle, 6, 2152-2160. https://doi.org/10.4161/cc.6.17.4633

7. Bachand, G.D., Spoerke, E.D. and Stevens, M.J. (2015) Microtubule-Based Nanomaterials: Exploiting Nature's Dynamic Biopolymers. Biotechnology and Bioengineering, 112, 1065-1073. https://doi.org/10.1002/bit.25569

8. Liew, K., Xiang, P. and Zhang, L. (2015) Mechanical Properties and Characteristics of Microtubules: A Review. Composite Structures, 123, 98-108. https://doi.org/10.1016/j.compstruct.2014.12.020

9. Kis, A., Kasas, S., Babić, B., Kulik, A., Benoit, W., Briggs, G., Schönenberger, C., Catsicas, S. and Forro, L. (2002) Nanomechanics of Microtubules. Physical Review Letters, 89, Article ID: 248101. https://doi.org/10.1103/PhysRevLett.89.248101

10. Kabir, A.M.R., Inoue, D., Hamano, Y., Mayama, H., Sada, K. and Kakugo, A. (2014) Biomolecular Motor Modulates Mechanical Property of Microtubule. Biomacromolecules, 15, 1797-1805.

https://doi.org/10.1021/bm5001789 
11. Li, S., Wang, C. and Nithiarasu, P. (2017) Three-Dimensional Transverse Vibration of Microtubules. Journal of Applied Physics, 121, Article ID: 234301. https://doi.org/10.1063/1.4986630

12. Li, S., Wang, C. and Nithiarasu, P. (2019) Electromechanical Vibration of Microtubules and Its Application to Biosensors. Journal of the Royal Society Interface, 16, Article ID: 20180826. https://doi.org/10.1098/rsif.2018.0826

13. Aria, I. and Biglari, H. (2018) Computational Vibration and Buckling Analysis of Microtubule Bundles Based on Nonlocal Strain Gradient Theory. Applied Mathematics and Computation, 321, 313-332. https://doi.org/10.1016/j.amc.2017.10.050

14. Kucera, O., Havelka, D. and Cifra, M. (2017) Vibrations of Microtubules: Physics That Has Not Met Biology Yet. Wave Motion, 72, 13-22. https://doi.org/10.1016/j.wavemoti.2016.12.006

15. Havelka, D., Deriu, M.A., Cifra, M. and Kucera, O. (2017) Deformation Pattern in Vibrating Microtubule: Structural Mechanics Study Based on an Atomistic Approach. Scientific Reports, 7, Article No. 4227. https://doi.org/10.1038/s41598-017-04272-w

16. Motamedi, M. and Mashhadi, M.M. (2016) Dynamic Simulation and Mechanical Properties of Microtubules. Journal of Solid Mechanics, 8, 781-787.

17. Wang, C.Y., Ru, C.Q. and Mioduchowski, A. (2006) Vibration of Microtubules as Orthotropic Elastic Shells. Physica E, 35, 48-56. https://doi.org/10.1016/j.physe.2006.05.008

18. Kim, J.W., Li, N., Pidaparti, R. and Wang, X.Q. (2018) Microtubular Protofilament Analysis Based on Molecular Level Tubulin Interaction. MCB Molecular and Cellular Biomechanics, 15, 127-141.

19. Pidaparti, R. and Jakkam, D. (2020) Mechanical Properties of Self-Assembled Microtubule Curved Protofilaments. Journal of Biomedical Science and Engineering, 13, 37-44. https://doi.org/10.4236/jbise.2020.133003

20. Mofrad, M.R. and Kamm, R.D. (2006) Cytoskeletal Mechanics: Models and Measurements in Cell Mechanics. Cambridge University Press, Cambridge.

21. Deriu, M.A., Enemark, S., Soncini, M., Montevecchi, F.M. and Redaelli, A. (2007) Tubulin: From Atomistic Structure to Supramolecular Mechanical Properties. Journal of Materials Science, 42, 8864-8872. https://doi.org/10.1007/s10853-007-1784-6

22. Peter, S.J. and Mofrad, M.R. (2012) Computational Modeling of Axonal Microtubule Bundles under Tension. Biophysical Journal, 102, 749-757. https://doi.org/10.1016/j.bpj.2011.11.4024

23. Zeiger, A. and Layton, B.E. (2008) Molecular Modeling of the Axial and Circumferential Elastic Moduli of Tubulin. Biophysical Journal, 95, 3606-3618. https://doi.org/10.1529/biophysj.108.131359

24. Odde, D.J., Ma, L., Briggs, A.H., DeMarco, A. and Kirschner, M.W. (1999) Microtubule Bending and Breaking in Living Fibroblast Cells. Journal of Cell Science, 112, 3283-3288. https://doi.org/10.1242/jcs.112.19.3283

25. Kononova, O., Kholodov, Y., Theisen, K., Marx, K.A., Dima, R.I., Ataullakhanov, F.I., Grishchuk, E. and Barsegov, V. (2014) Tubulin Bond Energies and Microtubule Biomechanics Determined from Nanoindentation in Silico. Journal of the American Chemical Society, 136, 17036-17045. https://doi.org/10.1021/ja506385p 